\title{
Competency-Based Learning. Teaching Gases
}

\author{
Adolfo Eduardo Obaya-Valdivia*, Carlos Montaño Osorio, Yolanda Marina Vargas Rodríguez
}

FES Cuautitlán UNAM, Chemistry Department, MADEMS, Mexico City, Mexico

Email: ^obaya@unam.mx

How to cite this paper: Obaya-Valdivia, A. E., Osorio, C. M., \& Rodríguez, Y. M. V. (2022). Competency-Based Learning. Teaching Gases. Creative Education, 13, 609-616. https://doi.org/10.4236/ce.2022.132037

Received: January 14, 2022

Accepted: February 19, 2022

Published: February 22, 2022

Copyright (c) 2022 by author(s) and Scientific Research Publishing Inc. This work is licensed under the Creative Commons Attribution International License (CC BY 4.0).

http://creativecommons.org/licenses/by/4.0/

\begin{abstract}
This paper seeks to evaluate learning based on the competency approach, taking a didactic experience to evaluate a possible improvement in the ability to solve problems and for autonomous learning in general. For the didactic development, the theme "gases" was taken, which is generally enunciated: Corpuscular kinetic theory of matter; State variables of a gas: P, V, T; Absolute temperature; General and State Equation of Ideal Gases Dalton's Law or Law of Partial Pressures; Ideal Gases and Real Gases; Van der Waals equation. For this purpose, the AIRBAG systems, and the determination of the normal molar volume of a gas are taken as the object of study.
\end{abstract}

\section{Keywords}

Competency-Based Learning, Gases, Equations of State, AIRBAG Systems, Normal Molar Volume

\section{Introduction}

The operational definition of competency-based education (CBE) is defined as an outcome-based approach to education that incorporates modes of instructional delivery and assessment efforts designed to evaluate mastery of learning by students through their demonstration of the knowledge, attitudes, values, skills, and behaviors required for the degree sought (Gervais, 2016).

This work focuses on the teaching of Physical Chemistry based on a competency-based approach. Therefore, it is essential to select some specific contents to guide with exercises and examples of problems the learning of the subject. It seeks to prioritize the development of autonomous, creative, and innovative, efficient, and effective learning, which allows solving and being able to raise new problems and questions close to reality. This can be facilitated by targeted internet searches to find the required data. The approach based on competences and knowledge descriptors raises as generic competences, among others, the follow- 
ing that can contribute to the development in chemistry courses at the upper middle and upper level:

1) Perform effectively in work teams;

2) Communicate effectively;

3) Learn continuously and autonomously.

The basic theoretical framework that supports the proposal is since the new learning material will only provoke the transformation of the student's beliefs and thoughts when it manages to: mobilize the already existing schemes of their thinking. The student should be taught in such a way that he can continue to learn in the future on his own. Coll (1994) states that Ausubel and his collaborators: "concretize the educational intentions through access to the contents, which requires having a deep knowledge of them to put together a hierarchical and relational scheme". All students can "significantly learn a content, provided that they have in their cognitive or cognitive structure, relevant and evener concepts" (Ausubel et al., 1983). The most important factor influencing learning is what the learner already knows.

The learning contents should be ordered in such a way that the most general and inclusive concepts are presented at the beginning to favor the formation of inclusive concepts in the cognitive structure. This is achieved through progressive differentiation and integrative reconciliation, which allow the content of the subject to be organized.

Progressive differentiation consists of first presenting the most general ideas of the subject, followed by a gradual increase in detail and specificity. Integrative reconciliation means that new concepts must be related to the content learned.

The didactic sequence must be organized in such a way that each successive learning is related to the previous ideas.

Professional competences require more active roles of both the student and the teacher, since they are oriented to autonomous learning that allows them to evolve in the construction of knowledge. Competencies are the skills or set of skills that allow the student to solve complex or integrative problems, in real scenarios, autonomously and with knowledge transfer to new situations (Hans-Joé et al., 2006; Giammatteo \& Obaya, 2018). From this perspective, the following general competencies are sought through the skills that allow to:

- Formulate and understand problems and situations, being able to create and develop strategies to solve them.

- Predict, estimate, and verify procedures and results, being able to describe and discuss them, using specific vocabulary.

- Know and be able to operate with the different chemical objects, using their relationships, properties, applications, generalizations, particularizations, and different forms of representation, using them to solve problems.

There are real-life problems that can be solved in a basic physical chemistry course. Problems must be chosen or created (Gonczi, 1994) according to the following criteria: 
1) they must capture the student through their interest and motivation,

2) they must be related to the real world so that students identify with it,

3) they must be contextualized through a problematic situation that makes them more attractive and challenging,

4) they must require reasoned decision-making, so that the student can negotiate and evaluate possible solutions,

5 ) they must be related to previous and subsequent knowledge,

6) the development of the problem must allow cooperative and collaborative work, that is, through strongly interrelated tasks, and discussion within the groups that involve the generation of hypotheses.

An AirBag is a safety device which is activated in a matter of milliseconds before a collision at strategic points of a car, inflating bags that cushion the impact of passengers, the phenomenon is due to sequential reactions that have gaseous nitrogen as products (Petrucci, 2010). Given the above, the objective of this work is to illustrate as an integrative problem $\mathrm{ABP}$ the reactions that take place to the formation of nitrogen gas that take place when the AirBag mechanism is activated, where the student analyzes, understands, and applies the definition of molar volume under Normal Conditions of Pressure and Temperature.

\section{Methodology}

The objective of the experience is to evaluate the teaching of gases, taking the didactic experience described as an example, for the improvement of learning and the ability to solve problems in this topic.

This proposal was applied in a group of basic thermodynamics of the chemical engineering career, in the Faculty of Higher Studies Cuautitlán UNAM (FES-C) with 48 students (55\% men and $45 \%$ women), with an average age of 19 years. All students were regular students, who had not previously studied thermodynamics.

Students are asked to group together three or four (Obaya, 1999), to discuss and list equipment or materials where substances in a gaseous state are present, such as refrigeration systems, air conditioning systems, polluting gases of industrial and vehicle emissions, among others.

They are informed that they have a time of five minutes and then must make a sharing, for which the teacher lists the examples on the board without issuing an opinion and only avoids repetitions. Once the examples are listed, each of them is analyzed and the characteristics of the gaseous state are discussed with the group.

The following are two cases by way of illustration teaching gases: 1) Airbag systems, 2) determination of normal molar volume. (To these topics the student must be taken)

\section{Discussion of Results}

\section{1) Airbag Systems}

The teacher must remember that the learning contents must be ordered in 
such a way that the most general and inclusive concepts are presented at the beginning to favor the formation of concepts including in the cognitive structure. This is achieved through progressive differentiation and integrative reconciliation, which make it possible to organize the content of the problem. Progressive differentiation consists of first presenting the most general ideas of the subject, followed by a gradual increase in detail and specificity. Integrative reconciliation means that new concepts must be related to the content learned.

Older airbag systems contained a mixture of sodium azide or sodium nitride $\left(\mathrm{NaN}_{3}\right)$, potassium nitrate $\left(\mathrm{KNO}_{3}\right)$, and silica $\left(\mathrm{SiO}_{2}\right)$.

A typical driver's side airbag contains about $50-80 \mathrm{~g}$ of $\mathrm{NaN}_{3}$, with the larger passenger-side airbag containing about $250 \mathrm{~g}$. Within 40 milliseconds of impact, all these components react according to three separate reactions that produce nitrogen gas (Petrucci, 2010). The reactions are presented in order based on the following schemes:

$$
\begin{gathered}
2 \mathrm{NaN}_{3(\mathrm{~s})} \rightarrow 2 \mathrm{Na}+3 \mathrm{~N}_{2(\mathrm{~g})} \\
10 \mathrm{Na}_{(\mathrm{s})}+2 \mathrm{KNO}_{3(\mathrm{~g})} \rightarrow \mathrm{K}_{2} \mathrm{O}_{(\mathrm{s})}+5 \mathrm{Na}_{2} \mathrm{O}_{(\mathrm{s})}+\mathrm{N}_{2(\mathrm{~g})} \\
\mathrm{K}_{2} \mathrm{O}_{(\mathrm{s})}+\mathrm{Na}_{2} \mathrm{O}_{(\mathrm{s})}+2 \mathrm{SiO}_{2(\mathrm{~s})} \rightarrow \mathrm{K}_{2} \mathrm{SiO}_{3(\mathrm{~s})}+\mathrm{Na}_{2} \mathrm{SiO}_{3(\mathrm{~s})} \text { (Silica powder) }
\end{gathered}
$$

With the help of the teacher the students will understand that the first chemical reaction is the decomposition of $\mathrm{NaN}_{3}$ under high temperature conditions using an electrical impulse that raises the temperature to $300^{\circ} \mathrm{C}$, which is necessary for the decomposition of $\mathrm{NaN}_{3}$ that produces $\mathrm{Na}$ metallic and gas $\mathrm{N}_{2}$. As $\mathrm{Na}$

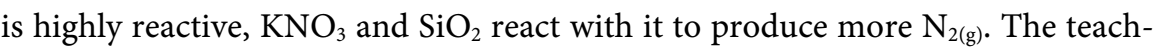
er will need to ask students the question of why $\mathrm{KNO}_{3}$ is used instead of $\mathrm{NaNO}_{3}$. The reason $\mathrm{KNO}_{3}$ is used instead of $\mathrm{NaNO}_{3}$ is because it is less hygroscopic (absorbs less water), as moisture can destabilize the system and cause failure. The potassium and sodium oxides $\mathrm{K}_{2} \mathrm{O}$ and $\mathrm{Na}_{2} \mathrm{O}$ produced in the above reactions react with $\mathrm{SiO}_{2}$ to produce a silicate powder that is a stable and non-hazardous compound.

New compounds are currently being analyzed and tested. The operation can be observed in detail in the web address:

https://www.youtube.com/watch?v=KRcajZHc6Yk consulted on October 17, 2021.

After watching the video, team students should answer the following questions and present their findings in a group plenary session.

- At what angle should the airbag hit the occupants of the vehicle?

- What would happen if the airbag is immersed in a non-Newtonian fluid and activated?

- How is the concept of momentum and inertia involved in the demonstration shown in the video?

Students are expected to discuss in groups the content of the suggested video that will serve to complete and expand the contents reviewed in the problem. Also, it is suggested that the teacher give suggestions about other concepts that 
are convenient to review to improve the understanding of the topic treated. It is recommended that the final reports be presented in the form of a poster, or some graphic organizer that exemplifies all the work done by the team, in a group session

\section{2) Determination of normal molar volume}

Students are asked to relate gas data listed in Table 1, for the calculation of normal molar volume and to formulate as many conclusions as possible. The teacher must remember that the learning contents must be ordered in such a way that the most general and inclusive concepts are presented at the beginning to favor the formation of concepts including in the cognitive structure. This is achieved through progressive differentiation and integrative reconciliation, which make it possible to organize the content of the problem. The teacher must remind students of the corpuscular kinetic theory of matter, as well as when a gas is under normal conditions of temperature and pressure. Differentiating them from the standard conditions of temperature and pressure (Smith et al., 2018), progressive differentiation consists of first presenting the most general ideas of the subject, followed by a gradual increase in detail and specificity. Integrative reconciliation means that new concepts must be related to the content learned.

Students are asked to determine the normal molar volume of at least five gases, understand their chemical structures, their physical and chemical properties, in pooling formulate hypotheses, contrast them by comparing their results, formulate and establish conclusions and infer gas applications under normal conditions.

Students calculated the normal molar volume by the ideal gas Equation (1)

$$
P V_{m}=R T
$$

where:

$$
P=\text { Pressure (atm) }
$$

Table 1. Molar volumes of different gases in CNPT.

\begin{tabular}{ccccc}
\hline Gas & Formula & $\begin{array}{c}\text { Molar mass } \\
(\mathrm{g} / \mathrm{mol})\end{array}$ & $\begin{array}{c}\text { Density CNPT } \\
(\mathrm{g} / \mathrm{L})\end{array}$ & $\begin{array}{c}\text { Normal molar volume } \\
(\mathrm{L} / \mathrm{mol})\end{array}$ \\
\hline Hydrogen & $\mathrm{H}_{2}$ & 2.02 & 0.090 & 22.428 \\
Helio & $\mathrm{He}$ & 4.003 & 0.178 & 22.426 \\
Neon & $\mathrm{Ne}$ & 20.18 & 0,900 & 22.425 \\
Nitrogen & $\mathrm{N}_{2}$ & 28.01 & 1.250 & 22.404 \\
Oxygen & $\mathrm{O}_{2}$ & 32.00 & 1.429 & 22.394 \\
Argon & $\mathrm{Ar}$ & 30.85 & 1.784 & 22.393 \\
Carbon Dioxide & $\mathrm{CO}_{2}$ & 44.01 & 1.977 & 22.256 \\
Ammonia & $\mathrm{NH}_{3}$ & 17.03 & 0.771 & 22.094 \\
Chlorine & $\mathrm{Cl}_{2}$ & 70.91 & 3.214 & 22.063 \\
\hline
\end{tabular}


$V_{m}=$ Molar volume $(\mathrm{L} / \mathrm{mol})$

$R=$ Universal gas constant $(0.08206 \mathrm{atmL} / \mathrm{molK})$

$T=$ Temperature $(\mathrm{K})$

For comparison with a real gas model, they obtained the volume with the Van der Waals equation, VDW, (2).

$$
\left(P+\frac{a}{V_{m}^{2}}\right)\left(V_{m}-b\right)=R T
$$

where:

$a$ and $b$ are characteristic VDW model constants for each substance, Table 2.

The students realized that it is not possible to isolate the molar volume of Equation (2), unlike the ideal gas equation, but it is possible to leave it as a cubic function (Equation (3)):

$$
V_{m}^{3}-\left(b+\frac{R T}{P}\right) V_{m}^{2}+\frac{a}{P} V_{m}-\frac{a b}{P}=0
$$

The cubic equation was found by the students using the Excel Solver.

As an instrument for data collection (Brilingaité et al., 2018), a rubric is suggested as an evaluation matrix in which the progress of each student is recorded according to the three generic competencies proposed:

1) perform effectively in work teams,

2) communicate effectively and

3) learn continuously and autonomously.

Students are expected to discuss in groups that will serve to complete and expand the revised contents on the issue. Also, it is suggested that the teacher give suggestions about other concepts that are convenient to review to improve the understanding of the topic treated. It is recommended that the final reports be presented in the form of a poster, or some graphic organizer that exemplifies all the work done by the team, in a group session (Table 3 ).

Table 2. Constants for VDW equation

\begin{tabular}{ccc}
\hline Gas & $a\left[\frac{L^{2} \mathrm{~atm}}{\mathrm{~mol}^{2}}\right]$ & $b\left[\frac{L}{\mathrm{~mol}}\right]$ \\
\hline Hydrogen & 0.24430 & 0.02661 \\
Helio & 0.03412 & 0.02370 \\
Neon & 0.21070 & 0.01709 \\
Nitrogen & 1.38956 & 0.03913 \\
Oxygen & 1.30994 & 0.03183 \\
Argon & 1.34514 & 0.03219 \\
Carbon Dioxide & 3.59232 & 0.04267 \\
Ammonia & 4.16965 & 0.03707 \\
Chlorine & 6.49282 & 0.05622 \\
\hline
\end{tabular}


Table 3. Evaluation rubric generic competences.

\begin{tabular}{cllllll}
\hline Generic competence & 1 & 2 & 3 & 4 & 5 \\
\hline Perform effectively in work teams & & & & & \\
Communicate effectively & & & & & & \\
Learning continuously and autonomously & & & & \\
\hline
\end{tabular}

\section{Conclusion}

In this didactic experience, general competencies are sought through the skills that allow to:

- Formulate and understand problems and situations, being able to create and develop strategies to solve them.

- Predict, estimate, and verify procedures and results, being able to describe and discuss them, using specific vocabulary.

- Know and be able to operate with the different chemical objects, using their relationships, properties, applications, generalizations, particularizations, and different forms of representation, use them to solve problems.

- Exemplify the concept and calculation of molar volume under Normal Conditions of Pressure and Temperature using the ABP example of Airbags.

In problem-solving teaching, the student must understand the problem, look for missing information, try to solve it, and exchange ideas with peers during the process.

The teacher acts as a facilitator, guide, and counselor in the search for solutions. Among its benefits: it increases motivation and promotes higher-order thinking, encourages learning to learn and promotes metacognition.

Some opinions of the students regarding the course are:

I like that we can work as a team because in several cases the doubts that were generated were resolved between us.

Very didactic, I think that teamwork is more practical, and we can solve our doubts among ourselves.

I liked the classes very much, because the teacher was always present to solve the doubts we had, as well as the examples were clear, and the explanation is easy to understand.

I basically liked the dynamics of the class; it was entertaining, albeit somewhat heavy.

Most of the doubts were solved and together with the companions it was easy to polish.

I was also helped using the different tools suggested in class, Excel, being a very important software for the breakdown of activities.

There are a good number of real-life problems that can be solved. The problems must be chosen or created according to the following criteria:

1) they must capture the student through their interest and motivation,

2) they must be related to the real world so that students identify with it, 
3) they must be contextualized through a problematic situation that makes them more attractive and challenging,

4) they must require reasoned decision-making, so that the student can negotiate and evaluate possible solutions,

5) they must be related to previous and subsequent knowledge,

6) the development of the problem must allow cooperative and collaborative work, that is, through strongly interrelated tasks, and discussion within the groups that involve the generation of hypotheses.

\section{Acknowledgements}

PAPIME PE: 101721 Aprendizaje basado en Problemas en línea. Fisicoquímica.

\section{Conflicts of Interest}

The authors declare no conflicts of interest regarding the publication of this paper.

\section{References}

Ausubel, D., Novak, D. J., \& Hanessian, H. (1983). Psicología educativa. Un punto de vista cognitivo. Trillas.

Brilingaité, A., Bukauskas, L., \& Juškevičienè, A. (2018). Competency Assessment in Problem-Based Learning Projects of Information Technologies Students. Informatics in Education, 17, 21-44. https://doi.org/10.15388/infedu.2018.02

Coll, C. (1994). Psicología y Curriculum. Paidós.

Gervais, J. (2016). The Operational Definition of Competency-Based Education. The Journal of Competency-based Education, 1, 98-106. https://doi.org/10.1002/cbe2.1011

Giammatteo, L., \& Obaya, V. A. (2018). Assessing Chemistry Laboratory Skills through a Competency Based Approach in High School Chemistry Course. Science Education International, 29, 103-109. https://doi.org/10.33828/sei.v29.i2.5

Gonczi, A. (1994). Competency Based Assessment in Professions in Australia. Assessment in Education, 1, 27-44. https://doi.org/10.1080/0969594940010103

Hans-Joè R. W., Alabart J. R., Giralt F., Herrero J., Vernis L., \& Medir M. (2006). A Competency-Based Educational Model in a Chemical Engineering School. International Journal of Enginnering Education, 22, 218-235.

Obaya, V. A. (1999). Getting Cooperative Group. Science Education International, 10, 25-27.

Petrucci, R. (2010). General Chemistry: Principles and Modern Applications (11th ed.). Pearson.

Smith, J. M., Van Ness, H. C., Abbott, M. M., \& Swihart, M. T. (2018). Introduction to Chemical Engineering Thermodynamics (8th ed.). McGraw-Hill Education.

\section{Video}

Airbag Deploying in Slow Mo - The Slow Mo Guys

https://www.youtube.com/watch?v=KRcajZHc6Yk consulted on October 17, 2021. 